EUROPEAN JOURNAL O ENVIRONMENT
European Journal of Environment and Public Health, 2018, 2(1), 03

ISSN: $2468-1997$

\title{
Factors Associated with HIV-Testing among African Americans: Analysis of the 2016 National Health Interview Survey
}

\author{
Audrey N. Funk ${ }^{1}$, Jeff N. Inungu ${ }^{1 *}$, Eric R. Leveille ${ }^{1}$, Mark Minelli ${ }^{1}$ \\ ${ }^{1}$ MPH Program, Central Michigan University, Mt. Pleasant, UNITED STATES
}

*Corresponding Author: jin202@gmail.com

Citation: Funk, A. N., Inungu, J. N., Leveille, E. R. and Minelli, M. (2018). Factors Associated with HIVTesting among African Americans: Analysis of the 2016 National Health Interview Survey. European Journal of Environment and Public Health, 2(1), 03. https://doi.org/10.20897/ ejeph/82621

Published: March 10, 2018

\begin{abstract}
African-Americans represent $12 \%$ of the total United States population, but account for more recent human immunodeficiency virus (HIV) diagnoses (44\%), people estimated to be living with HIV disease $(40 \%)$, and HIV-related deaths (44\%) than any other racial/ethnic group in the United States. This paper examines the prevalence of HIV testing and its correlates among African Americans during the pre-exposure HIV prophylaxis era. Secondary analysis of the 2016 National Health Interview Survey (NHIS) data was carried out using descriptive and logistic regression analyses to determine the prevalence of recent HIV testing and factors associated with HIV testing. Of the 33,028 individuals included in the Sample Adult Core, 3,777 $(11.43 \%)$ were African Americans, the sample for this study. Among them, an estimated 2,050 respondents $(54.3 \%)$ reported to have ever tested for HIV. Respondents aged 25 to 34 years of age were more likely to have ever tested for HIV compared to individuals aged 25 years or younger (OR: 2.47, P<0.001). Respondents who had a paid employment were more likely to have ever tested for HIV compared to those who were unemployed (OR: 1.74, $\mathrm{P}<0.05)$. There was no difference in HIV testing among the marital status categories. Since HIV testing is critical to improve prevention efforts, more research is needed to understand the characteristics of individuals who get tested for HIV to inform the design of innovative interventions to motivate younger adults and individuals from different marital status categories to seek HIV testing.
\end{abstract}

Keywords: HIV, testing, African Americans, correlates, USA

\section{BACKGROUND}

Although African-Americans represent only 12\% of the United States total population, they account for more recent human immunodeficiency virus (HIV) diagnoses (44\%), people estimated to be living with HIV disease $(40 \%)$, and HIV-related deaths (44\%) than any other racial/ethnic group in the U.S (Prevention CfDCa, 20162017). Behavioral, economic, and contextual factors contribute to the deepening of this disparity over time. The high HIV prevalence in African-American communities puts its members at higher risk of infection with each sexual encounter. The high HIV prevalence persists even when individual risk behaviors, such as sex without condoms, multiple sexual partners, and increased number of concurrent relationships, are consistent with other racial groups (Aral et al., 2008; Control CfD, Prevention, 2015; Hallfors et al., 2007). However, higher prevalence of sexually transmitted diseases (STDs) in African-Americans compared to other racial/ethnic groups may contribute to the high transmission of HIV among African-Americans (Control CfD, Prevention, 2015). Additionally, social and structural factors including: poverty, limited educational opportunities and attainment, high rates of incarceration, unrelenting stress, lack of access to medical and dental care, and racism in its many forms, continue to fuel HIV transmission among African Americans (McCree, 2009). Furthermore, the prevalence of 
stigma and homophobia in African-American communities push men who are ashamed of their sexuality to seek discrete sexual relations with other men while remaining involved in monogamous relationships with women. This phenomenon, known as "down low phenomenon" plays a critical role in the spread of HIV in the black communities (Stone, 2011).

It is estimated that nearly $40 \%$ of individuals living with HIV in the United States are unaware of their status (WHO|HIV/AIDS, 2017). Individuals who learn that they are HIV positive are much more likely to engage in protective behaviors to reduce the risk of transmission (No Author, 2017). HIV diagnosis is essential as the entry point for a lifelong continuum of care and treatment that benefits the health, quality of life, and life expectancy of the infected person and reduces the likelihood of HIV transmission to others (Marks et al., 2005; Cohen et al., 2011). Although HIV testing rates increased among adults from $40 \%$ between 2001 and 2006 to $45 \%$ in 2009 (Johnson et al., 2010), a large portion of the U.S. population has never been tested for HIV. National studies indicate that as many as 60-68\% of African Americans have been tested for HIV at some point in their lifetime as compared to $42-49 \%$ of Whites (Johnson et al., 2010; Anderson et al., 2005). Despite increasing overall HIV testing rates, African Americans are more likely to have delayed HIV diagnosis and treatment, as compared to Whites (Marks et al., 2005; Hall et al., 2015). African Americans with HIV are also less likely to receive antiretroviral therapy than people of other races (Gebo et al., 2005). Low perceived risk, fear of testing positive, and stigma are the major deterrent to testing for HIV among African Americans (Adams et al., 2003; Kellerman et al., 2002; Nunn et al., 2011).

Persons unaware of their human immunodeficiency virus (HIV) infection contribute nearly one third of ongoing transmission in the United States (Marks et al., 2005). To advance the goals of the National HIV/AIDS Strategy (i.e., reducing new HIV infections, improving health outcomes among persons living with HIV, and reducing HIV-related disparities), CDC and its partners have been pursuing a prevention approach to maximize the impact of current HIV testing efforts (Hall et al., 2015).

Several prevention strategies ranging from raising awareness about modes of HIV transmission to promoting pre-exposure HIV prophylaxis (PrEp) have been developed to curb the spread of HIV infection (Hayman and Callister, 2006; Smith et al., 2012). Recent data indicate some encouraging trends, including a decline in new HIV diagnoses among African-Americans overall, especially among women, and a leveling off of new diagnoses among Black homosexual and bisexual men (Control CfD, Prevention, 2013). However, given the epidemic's continued impact among African-Americans, an ongoing assessment of HIV transmission in this community is paramount to controlling the epidemics in the United States. Randomized clinical trials of a daily oral regimen of antiretrovirals used as pre-exposure prophylaxis (PrEP) for the prevention of HIV-1 acquisition have demonstrated efficacy in women and men from diverse settings (Grant et al., 2010; Baeten et al., 2012). PrEP can help prevent HIV infection in people who don't have HIV, but who are at high risk of becoming infected with HIV. The health benefit of PrEP can motivate people who are at high risk for HIV to seek testing to take advantage of this new preventive technology. The purpose of this study is to examine the prevalence of HIV testing and its correlates among African Americans during the PrEP era.

\section{METHODS}

\section{Data Source}

This study is the secondary analysis of data derived from the 2016 National Health Interview Survey (NHIS) public use file. The NHIS is an ongoing annual health survey conducted by the National Center for Health Statistics (NCHS), Centers for Disease Control and Prevention (CDC). NHIS is a nationally representative health survey of the civilian, noninstitutionalized population aged 18 years and older and serves as one of the most comprehensive resources on health in the United States. The NHIS sampling and data collection methods have been described elsewhere (Parsons et al., 2014). The NHIS has four main modules: The Household Composition Section, Family Core, Sample Adult Core, and Sample Child Core. The Household Composition Section collects basic demographic and relationship information about all persons in the household. The Family Core questionnaire collects information on sociodemographic characteristics, basic indicators of health status, health insurance coverage, and access to and utilization of health care services from all persons in each family in the household. From each participating family, one sample child (if there are any children aged 17 years and under) and one sample adult aged 18 years and over are randomly selected. Information on each is collected with the Sample Child and Sample Adult questionnaires, respectively. The Sample Adult Core interview collects additional data on health status and conditions, health behaviors, functioning and disability, and access to and utilization of health care services.

Data were collected by trained interviewers with the U.S. Census Bureau using computer-assisted personal interviewing (CAPI), a data collection method in which an interviewer meets with respondents face-to-face to ask 
European Journal of Environment and Public Health, 2(1), 03

Table 1. Socio-demographic characteristics of the study sample

\begin{tabular}{|c|c|c|c|c|c|c|c|c|}
\hline \multicolumn{2}{|l|}{ Characteristics } & \multicolumn{2}{|c|}{$\begin{array}{c}\text { Male } \\
\mathrm{N}=1431(\%)\end{array}$} & \multicolumn{2}{|c|}{$\begin{array}{c}\text { Female } \\
\mathrm{N}=2346(\%)\end{array}$} & \multirow{2}{*}{$\begin{array}{c}\begin{array}{c}\text { Total } \\
\mathbf{N}=3777\end{array} \\
397\end{array}$} & \multirow{2}{*}{$\begin{array}{c}\text { Chi-Square } \\
7.04\end{array}$} & \multirow{2}{*}{$\begin{array}{c}\mathbf{P} \\
0.13\end{array}$} \\
\hline \multirow{5}{*}{ Age } & $\leq 25$ & 153 & 38.5 & 244 & 61.5 & & & \\
\hline & $25-34$ & 225 & 34.5 & 428 & 65.5 & 653 & & \\
\hline & $35-44$ & 224 & 38.4 & 360 & 61.6 & 584 & & \\
\hline & $45-54$ & 266 & 41.5 & 375 & 58.5 & 641 & & \\
\hline & $\geq 55$ & 563 & 37.5 & 939 & 62.5 & 1502 & & \\
\hline \multirow{3}{*}{ Marital status } & Married & 582 & 51.1 & 558 & 48.9 & 1140 & 124.4 & 0.00 \\
\hline & Separated & 360 & 38.5 & 821 & 69.5 & 1181 & & \\
\hline & Single & 481 & 33.3 & 963 & 66.7 & 1444 & & \\
\hline \multirow{4}{*}{ Region } & Northeast & 178 & 37.9 & 291 & 62.0 & 469 & 6.34 & 0.07 \\
\hline & Midwest & 224 & 40.8 & 325 & 59.2 & 549 & & \\
\hline & South & 901 & 36.6 & 1560 & 63.4 & 2461 & & \\
\hline & West & 128 & 42.9 & 170 & 57.0 & 298 & & \\
\hline \multirow{2}{*}{ Employment } & Not working & 624 & 35.5 & 1134 & 64.5 & 1758 & 8.06 & 0.005 \\
\hline & Working & 807 & 39.9 & 1211 & 60.1 & 2018 & & \\
\hline \multirow{2}{*}{ Ever tested for HIV } & No & 665 & 38.5 & 1062 & 61.5 & 1727 & 0.54 & 0.47 \\
\hline & Yes & 766 & 37.4 & 1284 & 62.6 & 2050 & & \\
\hline
\end{tabular}

questions and enter the answers into a laptop computer. When necessary, interviewers completed missing portions of the interview over the telephone. In 2016, NHIS interviews were conducted in 33,676 households with the response rate of $67.9 \%$.

\section{Study Sample}

Our study sample was drawn from the Sample Adult Core. Respondents who reported being black or African American were included in this analysis. Those who reported more than one race were excluded. Of the 33,028 individuals included in the Sample Adult Core, 3,777 (11.43\%) were African Americans. Respondents 18 years or older were asked, "Have you ever tested for HIV?" We classified respondents as ever tested for HIV (54.3\%) and never tested for HIV (45.72\%). Having ever tested for HIV was our outcome of interest or our dependent variable.

\section{Measures}

Independent variables for this analysis included the demographic and socioeconomic variables: age $(<25$ years, $25-34,35-44,45-54$, and 55 years and older), sex, educational attainment (<high school, high school, and $\geq$ some college), marital status (living in union, separated/divorced/widow), employment status during the last 12 months, and the region of the United States where they live (Northeast, Midwest, South or West) and sexual orientation.

\section{Data Analysis}

Descriptive analysis was performed to compare demographic and socioeconomic variables between men and women as well as between respondents who ever tested and those who never tested for HIV. Student $\mathrm{t}$ test was used for quantitative measures and chi-square was used to test for statistically significant differences in categorical variables. Multivariate regression was performed to estimate bivariate association between independent variables and HIV testing. Logistic regression was also used to calculate multivariate-adjusted odds ratios (OR) and their 95\% confidence intervals (CI) while adjusting for potential confounding. Collinear variables were excluded from the analyses. Statistical analyses were performed using Stata/SE 13.0 (StataCorp, 2013: Stata Statistical Software, Release 13.0, College Station, TX: StataCorp LP) and a p-value of less than 0.05 was considered significant unless otherwise specified.

\section{RESULTS}

\section{Participant Characteristics}

Table 1 shows the sociodemographic characteristics of the participants. Among the 3,777 African-Americans who participated in the 2016 NHIS, $62.2 \%$ were women. The age ranged from 18 to 85 years, with a mean age of 48.7 years (SD: 17.3 years) for men compared to 48.7 years (SD: 18.4 years) for women. Most participants $(\mathrm{n}=1502)$ were 55 years old or more.

Regarding their marital status, 1,140 (30.2\%) participants lived in union (married or living with a partner). More men lived in union $(51.1 \%)$ than women $(48.9 \%)$. A high proportion of women were single $(66.7 \%)$ compared to men $(33.3 \%)$. The South accounted for most participants (65.1\%), followed by Midwest with $14.5 \%$. During the 12 months preceding the interview, $53.4 \%$ of participants held a paid position. More women $(60.1 \%)$ reported working than men $(39.9 \%)$. Furthermore, women were asked if they were pregnant at the time of the interview. 
Table 2. Factors associated with HIV testing among African-Americans in 2016

\begin{tabular}{|c|c|c|c|c|c|c|c|c|}
\hline \multicolumn{2}{|c|}{ Characteristics } & \multicolumn{2}{|c|}{$\begin{array}{c}\text { Never tested for HIV } \\
\mathrm{n}=1727(\%)\end{array}$} & \multicolumn{2}{|c|}{$\begin{array}{c}\text { Ever tested for HIV } \\
n=2050(\%)\end{array}$} & \multirow{2}{*}{$\begin{array}{c}\begin{array}{c}\text { Unadjusted Odds } \\
\text { Ratio }\end{array} \\
1\end{array}$} & \multirow[t]{2}{*}{$95 \% \mathrm{CI}$} & \multirow[t]{2}{*}{$\mathbf{P}$} \\
\hline \multirow{2}{*}{ Sex } & Male & 665 & 38.5 & 766 & 37.4 & & & \\
\hline & Female & 1062 & 61.5 & 1284 & 62.6 & 1.04 & $0.83-1.19$ & 0.51 \\
\hline \multirow{5}{*}{ Age groups } & $\leq 25$ & 211 & 12.2 & 186 & 9.1 & 1 & & \\
\hline & $25-34$ & 205 & 11.9 & 448 & 21.9 & 2.47 & $1.91-3.20$ & $0.00^{* * *}$ \\
\hline & $35-44$ & 156 & 9.0 & 428 & 20.9 & 3.11 & $2.51-4.07$ & $0.00^{* * *}$ \\
\hline & $45-54$ & 263 & 15.2 & 378 & 18.4 & 1.63 & $1.26-2.09$ & $0.00^{* * *}$ \\
\hline & $\geq 55$ & 892 & 51.6 & 610 & 29.7 & 0.77 & $0.62-0.96$ & $0.02^{*}$ \\
\hline \multirow{3}{*}{ Marital status } & Living in union & 510 & 26.9 & 630 & 30.8 & 1 & & \\
\hline & Separated & 590 & 343 & 591 & 28.9 & 0.81 & $0.68-0.95$ & $0.01 * *$ \\
\hline & Single & 618 & 35.9 & 826 & 40.4 & 1.08 & $0.92-1.26$ & 0.32 \\
\hline \multirow{4}{*}{ Region } & Northeast & 207 & 11.9 & 262 & 12.8 & 1 & & \\
\hline & Midwest & 258 & 14.9 & 291 & 14.2 & 0.89 & $0.69-1.14$ & 0.36 \\
\hline & South & 1138 & 65.9 & 1323 & 64.5 & 0.91 & $0.75-1.12$ & 0.40 \\
\hline & West & 124 & 7.2 & 174 & 8.5 & 1.10 & $0.82-1.48$ & 0.49 \\
\hline \multirow{2}{*}{ Employment } & Not working & 993 & 54.1 & 825 & 40.2 & 1 & & \\
\hline & Working & 793 & 45.9 & 1225 & 59.8 & 1.74 & $1.53-1.98$ & $0.00^{* * *}$ \\
\hline
\end{tabular}

$* \mathrm{p}<0.05^{* *} \mathrm{p}<0.01 * * * \mathrm{p}<0.001$

Table 3. Factors associated with HIV testing among African-Americans in 2016

\begin{tabular}{|c|c|c|c|c|}
\hline Characteristics & & Adjusted OR & $95 \% \mathrm{CI}$ & $\mathbf{P}$ \\
\hline \multirow{2}{*}{ Sex } & Male & 1 & & \\
\hline & Female & 1.03 & $0.90-1.19$ & 0.60 \\
\hline \multirow{6}{*}{ Age groups } & $\leq 25$ & 1 & & \\
\hline & $25-34$ & 2.39 & $1.83-3.10$ & $0.00^{* * *}$ \\
\hline & $35-44$ & 2.94 & $2.22-3.89$ & $0.00^{* * *}$ \\
\hline & $45-54$ & 1.55 & $1.18-2.03$ & $0.00 * * *$ \\
\hline & $\geq 55$ & 0.75 & $0.58-0.97$ & $0.03^{*}$ \\
\hline & Living in Union & 1 & & \\
\hline \multirow{2}{*}{ Marital status } & Separated & 1.15 & $0.96-1.37$ & 0.11 \\
\hline & Single & 1.00 & $0.84-1.19$ & 0.01 \\
\hline \multirow{2}{*}{ Employment } & Not working & 1 & & \\
\hline & Working & 1.17 & $1.01-1.35$ & $0.03^{*}$ \\
\hline
\end{tabular}

† Odds ratios for these variables reflect the expected change in odds of recent testing for a one standard deviation increase in the variable. $* \mathrm{p}<0.05 * * \mathrm{p}<0.01 * * * \mathrm{p}<0.001$

Among the 1,203 women responded to the question, 38 (3.16\%) were pregnant. Of all the adult participants interviewed, $54.3 \%$ had ever been tested for HIV.

\section{Variables associated with HIV testing}

Table 2 shows the results of the bivariate associations between ever testing for HIV and selected independent variables (Unadjusted results). Older age 25-34 years (OR: 2.47); 35 - 44 years (OR: 3.11), and 45-54 years (OR: 1.63); being employed (OR: 1.74) were positively associated with having been tested for HIV. However, being 55 years or older (OR: 0.77 ) and being divorced/separated or widow (OR: 0.81 ) were negatively associated with having been tested for HIV.

Table 3 shows adjusted associations between the outcome of interest (ever tested for HIV) and the independent variables. Variables found to be associated with the outcome in the bivariate analysis (except the variable sex) were entered in the regression model. Although women (OR: 1.01, p >0.05) were slightly more likely than men to report ever testing for HIV, the association was not statistically significant. Participants ages 25-34 years (OR: 2.39, $\mathrm{p}<0.001)$; $35-44$ years (OR: 2.94, $\mathrm{p}<0.001)$; or $45-54$ years (OR: $1.55, \mathrm{p}<0.001)$ were significantly more likely to have ever tested for HIV than those younger than 25 years. However, individuals aged 55 years or more $(\mathrm{OR}: 0.75, \mathrm{p}<0.05)$ were significantly less likely than those younger than 25 years old to have ever tested for HIV.

After adjusting for other variables, being separated/divorced/widow (OR: 1.15, $\mathrm{p}>0.05$ ) was no longer significantly associated with having ever tested for HIV. Participants who reported having a paid employment in the last 12 months were more likely than those who did not to have ever tested for HIV (OR: 1.17, $\mathrm{p}<0.05$ ). 


\section{DISCUSSION}

The results of this analysis showed a significant association between older age and ever being tested for HIV. Respondents aged 25 to 34 years were more likely to have ever tested for HIV compared to those younger than 25 years (OR: 2.47, $\mathrm{p}<0.001)$. Our results support previous findings by Benavides-Torres, Wall, Rocha, Rodríguez, Hopson (Benavides-Torres et al., 2012). According to the Centers for Disease Control and Prevention (CDC), $61 \%$ of the persons diagnosed with HIV in the United States in 2015 were between the ages of 20 to 39 years (HIV in the United States, 2017). It is alleviating to know that individuals in this age group (25 to 34 years), known to be at high risk for HIV, were also likely to seek HIV testing. However, individuals who tested positive at age 20 must have been infected at a younger age. African American adolescents tend to engage in sexual intercourse at a younger age and are at greater risk for STI and HIV than other racial/ethnic groups in the U.S (Hallfors et al., 2007; Biello et al, 2013; Browning et al., 2004). More efforts are needed to motivate African American adolescents to get tested early.

The second finding of this study is the lack of difference in HIV testing among the different categories of marital status. This finding raised concerns considering the strong association between marital status and HIV death. In the literature, divorced and separated individuals were more likely to have tested for HIV than married individuals (Benavides-Torres et al., 2012; Inungu et al., 2011). Divorced and separated individuals were over 4 times more likely to die of HIV/AIDS than married individuals. Single or never married persons were 13 times more likely to die of HIV/AIDS as their married counterparts (Kposowa, 2013a; Kposowa, 2013b). Because of their wider sexual network, single/never married persons and the divorced/separated are at high risk of acquiring HIV/AIDS and subsequently dying from it (Klovdahl et al., 1994). Marriage seems to confer a form of social control (Kposowa, 2000; Harawa et al., 2003), which in effect works to limit the number of sexual partners that a spouse in the union may legally have. To get individuals at high risk (single and divorced) to seek HIV testing, behavior change communications should target these individuals to get them to seek HIV testing, the cornerstone for HIV prevention.

The association between HIV testing and employment has never been consistent in the literature. While our results showed that African Americans who were employed were more likely than not to have tested for HIV (OR: 1.17, $\mathrm{p}<0.05$ ), other reports indicated no difference in HIV testing by employment status (Benavides-Torres et al., 2012). Since the vast majority of HIV testing is conducted in doctor's offices, people who are unemployed may be less likely to have been tested due to their lack of employer provided healthcare coverage (Petroll et al., 2009; Simmons et al., 2005). Even where HIV testing is free such as in public health clinics, people who are unemployed lack the means of transportation to reach these clinics. In some industries, such as the healthcare, arm forces etc., HIV testing may be part of the employment process. The hiring agencies often time pay for the cost of medical exams and tests. Understandably, people are often reluctant to test because the discovery of a positive HIV test result may lead to the loss of employment and housing, dismissal from school, and denial of health/ life insurance and health care (Young and Bendavid, 2010; Maher, 2013). Requiring an HIV test raises many ethical issues regarding an individual's privacy. Employment of persons with life-threatening conditions such as HIV/AIDS will predictably have a significant impact at the workplaces. However, HIV is considered a disability and people with disabilities are legally protected from discrimination. The true association between employment and HIV testing needs to be clarified in future study.

Utilization of the large NHIS data set, which is representative of nearly the entire U.S population, is one strength of this study. However, it does have several limitations. First, the sample did not include institutionalized or incarcerated individuals. This is concerning based on the high risk for HIV transmission among prisoners. Incarceration contributes to high-risk sex behaviors and increased numbers of sexual partners which increases exposure to HIV (Knittel et al., 2013). Additionally, incarcerated men are likely to have sexual relationships with other men while incarcerated, which poses the greatest risk for HIV transmission (Knittel et al., 2013). In 2010 the rate of diagnosed HIV infection among inmates in state and federal prison was five times greater than the rate among individuals who were not incarcerated (HIV among Incarcerated Populations, 2017). Second, the selfreporting methods used to collect data for the NIHS may result in biased results through underreporting of HIV testing due to the stigma surrounding HIV. Finally, the NIHS data set lacks some vital demographic characteristics such as income and educational attainment, and resiliency factors such as social support and self-efficacy, which likely have a substantial impact on testing within the population. 


\section{CONCLUSION}

Since HIV testing is critical to improve prevention efforts, more research is needed to understand the characteristics of individuals who get tested for HIV to inform the design of innovative interventions to motivate younger adults and individuals from different marital status categories to seek HIV testing. Additionally, more researches are needed to clarify the association between employment and HIV testing.

\section{REFERENCES}

Adams, A. L., Becker, T. M., Lapidus, J. A., Modesitt, S. K., Lehman, J. S. and Loveless, M. O. (2003). HIV infection risk, behaviors, and attitudes about testing: are perceptions changing? Sexually transmitted diseases, 30(10), 764-768. https:// doi.org/10.1097/01.OLQ.0000078824.33076.45

Anderson, J. E., Chandra, A., Mosher and W. D. (2005). HIV testing in the United States, 2002: US Department of Health and Human Services, Centers for Disease Control and Prevention, National Center for Health Statistics.

Aral, S. O., Adimora, A. A. and Fenton, K. A. (2008). Understanding and responding to disparities in HIV and other sexually transmitted infections in African Americans. The Lancet, 372(9635), 337-340. https://doi.org/10.1016/S0140-6736(08)61118-6

Baeten, J. M., Donnell, D., Ndase, P., et al. (2012). Antiretroviral prophylaxis for HIV prevention in heterosexual men and women. The New England journal of medicine, 2012(367), 399-410. https:// doi.org/10.1056/NEJMoa1108524

Benavides-Torres, R. A., Wall, K. M., Rocha, G. M. N., Rodríguez, D. J. O. and Hopson, L. (2012). Factors associated with lifetime HIV testing in Texas by race/ethnicity. The open AIDS Journal, 6, 232.

Biello, K. B., Ickovics, J., Niccolai, L., Lin, H. and Kershaw, T. (2013). Racial Differences in Age at First Sexual Intercourse: Residential Racial Segregation and the Black-White Disparity among U.S. Adolescents. Public Health Rep., 128(Suppl 1), 23-32. https://doi.org/10.1177/00333549131282S103

Browning, C. R., Leventhal, T. and Brooks-Gunn, J. (2004). Neighborhood context and racial differences in early adolescent sexual activity. Demography, 41(4), 697-720. https://doi.org/10.1353/dem.2004.0029

Cohen, M. S., Chen, Y. Q., McCauley M, et al. (2011). Prevention of HIV-1 infection with early antiretroviral therapy. New England journal of medicine, 365(6), 493-505. https://doi.org/10.1056/NEJMoa1105243

Control CfD, Prevention. (2013). HIV surveillance report: diagnoses of HIV infection in the United States and dependent areas, 2011. [cited 2013 Jun 11].

Control CfD, Prevention. (2015). CDC fact sheet: HIV among African Americans.

Gebo, K. A., Fleishman, J. A., Conviser, R., et al. (2005). Racial and gender disparities in receipt of highly active antiretroviral therapy persist in a multistate sample of HIV patients in 2001. JAIDS Journal of Acquired Immune Deficiency Syndromes, 8(1), 96-103. https://doi.org/10.1097/00126334-200501010-00017

Hall, H. I., An, Q., Tang, T., et al. (2015). Prevalence of diagnosed and undiagnosed HIV infection-United States, 2008-2012. MMWR. Morbidity and mortality weekly report, 64(24), 657-662.

Hallfors, D. D., Iritani, B. J., Miller, W. C. and Bauer, D. J. (2007). Sexual and drug behavior patterns and HIV and STD racial disparities: the need for new directions. American journal of public health, 97(1), 125-132. https:// doi.org/10.2105/AJPH.2005.075747

Harawa, N. T., Greenland, S., Cochran, S. D., Cunningham, W. E. and Visscher, B. (2003). Do differences in relationship and partner attributes explain disparities in sexually transmitted disease among young white and black women? Journal of Adolescent Health, 32(3), 187-191. https:// doi.org/10.1016/S1054-139X(02)00458-5

Hayman, L. L. and Callister, L. C. (2006). HIV/STD Risk Reduction Interventions for African American and Latino Adolescent Girls at an Adolescent Medicine Clinic: A Randomized Controlled Trial. MCN: The American Journal of Maternal/Child Nursing, 31(1), 65. https:/ / doi.org/10.1097/00005721-200601000-00018

HIV among Incarcerated Populations | HIV by Group | HIV/AIDS | CDC. (2017).

HIV in the United States | Statistics Overview | Statistics Center | HIV/AIDS | CDC. (2017). 2017-0908T04:47:01Z. https://doi.org/10.2174/1874613601206010232

Inungu, J., Lewis, A., Younis, M. Z., Wood, J., O’Brien, S. and Verdun, D. (2011). HIV testing among adolescents and youth in the United States: update from the 2009 behavioral risk factor surveillance system. The open AIDS Journal, 5, 80. https://doi.org/10.2174/1874613601105010080

Grant, R. M., Lama, J. R., Anderson, P. L., et al. (2010). Preexposure chemoprophylaxis for HIV prevention in men who have sex with men. New England Journal of Medicine, 363(27), 2587-2599. https:// doi.org/10.1056/NEJMoa1011205

Johnson, A. S., Heitgerd, J., van Koenig, L., et al. (2010). Vital signs: HIV testing and diagnosis among adultsUnited States, 2001-2009. Morbidity and Mortality Weekly Report, 59(47), 1550-1555. 
Kellerman, S. E., Lehman, J. S., Lansky, A., et al. (2002). HIV testing within at-risk populations in the United States and the reasons for seeking or avoiding HIV testing. Journal of acquired immune deficiency syndromes (1999), 31(2), 202-210. https://doi.org/10.1097/00126334-200210010-00011

Klovdahl, A. S., Potterat, J. J., Woodhouse, D. E., Muth, J. B., Muth, S. Q. and Darrow, W. W. (1994). Social networks and infectious disease: The Colorado Springs study. Social science \& medicine, 38(1), 79-88. https://doi.org/10.1016/0277-9536(94)90302-6

Knittel, A. K., Snow, R. C., Griffith, D. M. and Morenoff, J. (2013). Incarceration and Sexual Risk: Examining the Relationship between Men's Involvement in the Criminal Justice System and Risky Sexual Behavior. AIDS Behav., 17(8), 2703-2714. https:/ / doi.org/10.1007/s10461-013-0421-4

Kposowa, A. J. (2000). Marital status and suicide in the National Longitudinal Mortality Study. Journal of Epidemiology \& Community Health, 54(4), 254-261. https:// doi.org/10.1136/jech.54.4.254

Kposowa, A. J. (2013). Marital status and HIV/AIDS mortality: evidence from the US National Longitudinal Mortality Study. Int J Infect Dis. Oct, 17(10), 868-874. https:// doi.org/10.1016/j.ijid.2013.02.018

Maher D. (2013). The ethics of feedback of HIV test results in population-based surveys of HIV infection. Bulletin of the World Health Organization, 91(12), 950-956. https:/ / doi.org/10.2471/BLT.13.117309

Marks, G., Crepaz, N., Senterfitt, J. W. and Janssen, R. S. (2005). Meta-analysis of high-risk sexual behavior in persons aware and unaware they are infected with HIV in the United States: implications for HIV prevention programs. JAIDS Journal of Acquired Immune Deficiency Syndromes, 39(4), 446-453. https://doi.org/10.1097/01.qai.0000151079.33935.79

McCree, D. H. (2009). A plan of action for tackling HIV/AIDS among African Americans. American journal of public bealth, 99(6), 972. https://doi.org/10.2105/AJPH.2009.162727

No Author. (2017). Adoption of Protective Behaviors among Persons with Recent HIV Infection and DiagnosisAlabama, New Jersey, and Tennessee, 1997-1998. JAMA, 284(2), 171-173.

Nunn, A., Zaller, N., Cornwall, A., et al. (2011). Low perceived risk and high HIV prevalence among a predominantly African American population participating in Philadelphia's Rapid HIV testing program. AIDS patient care and STDs., 25(4), 229-235. https://doi.org/10.1089/apc.2010.0313

Parsons, V. L., Moriarity, C. L., Jonas, K., Moore, T. F., Davis, K. E. and Tompkins, L. (2014). Design and estimation for the national health interview survey, 2006-2015.

Petroll, A. E., DiFranceisco, W., McAuliffe, T. L., Seal, D. W., Kelly, J. A. and Pinkerton, S. D. (2009). HIV Testing Rates, Testing Locations, and Healthcare Utilization among Urban African-American Men. J Urban Health, 86(1), 119-131. https://doi.org/10.1007/s11524-008-9339-y

Prevention CfDCa. (2016-2017). HIV Surveillance Report.

Simmons, E. M., Rogers, M. L., Frierson, G. M., Beckwith, C. G. and Flanigan, T. P. (2005). Racial/ethnic attitudes towards HIV testing in the primary care setting. J Natl Med Assoc., 97(1), 46-52.

Stone, B. E. (2011). The down low and the sexuality of race. Foucault Studies, 12, 36-50. https://doi.org/10.22439/fs.v0i12.3332

Smith, D. K., Toledo, L., Smith, D. J., Adams, M. A. and Rothenberg, R. (2012). Attitudes and program preferences of African-American urban young adults about pre-exposure prophylaxis (PrEP). AIDS Education and Prevention, 24(5), 408-421. https:// doi.org/10.1521/aeap.2012.24.5.408

WHO|HIV/AIDS. WHO. (2017). 2017-09-28 07:35:16. 